\title{
KEBIJAKAN KOMISI PENYIARAN INDONESIA TERHADAP KONTEN TELEVISI EDISI RAMADHAN
}

\author{
Ahmad Hayyan Najikh \\ Institut Agama Islam Negeri Jember \\ email : najikhahmad_kpi@iain-jember.ac.id \\ Muhammad Ardy Zaini \\ Institut Agama Islam Negeri Jember \\ email: iniazardy@gmail.com
}

\section{ABSTRACT}

The research entitled " THE KPI POLICY IN THE TELEVISION INDUSTRY (Case Study of KPI Policy on Content of Television Broadcasting Program Ramadhan Edition)" is motivated by the lack of maximum role of the government in creating situations and conditions conducive to worship in the month of Ramadan, especially in the realm of television media broadcasting the Ramadan edition)". The concrete form is that some of the da'wah programs on television present more shows than guidance, some deviate to the point of lacking in everyday examples. Whereas television, if seen from the perspective of da'wah, can be said to be an effective da'wah media. And the role of government here is institutionally represented by KPI (Indonesian Broadcasting Commission). This study aims to find out exactly how the Indonesian Broadcasting Commission's policies towards television media content, especially during the month of Ramadan. Because of KPI's findings, found violations committed by television media are a repetition of previous years. This research is a qualitative study using policy analysis as a methodology for analyzing KPI policies, which includes collecting data from online news, the Broadcasting Law, KPI's official website and MUI statement, and then analyzing the findings. The results show that if theoretically, the policies issued by KPI institutions are legally strong and must be obeyed by all parties related to KPI institutions. But in reality there are still those who have not yet implemented it. And when related to the theories above, the factors that cause implementation to fail are due to factors such as the selection of the wrong strategy, or the wrong "machine" or "instrument"; "Programming" bureaucracy is wrong; the operation operation is bad; there is something wrong at the "executive level"; or a bad response to a problem. From these factors, it could be that the factors within the KPI are the poor level of implementing policies. The lack of strict sanctions provided, so that KPI institutions do not have the authority in the eyes of media stakeholders. And can also be bad bureaucratic instruments.

Keywords: Television, KPI (Indonesian Broadcasting Commision), policy, Broadcasting Law.

\section{PENDAHULUAN}

Bulan Ramadhan adalah bulan yang suci bagi umat muslim. Dinamakan bulan suci karena bulan Ramadhan adalah bulannya Allah SWT. Maksudnya bahwa didalam bulan 
ramadhan Allah melimpahkan banyak keistimewaan dan keutamaan. Diantaranya, ada satu malam yang lebih baik dari seribu bulan; bulan ini penuh berkah, berdayaguna dan bermanfaat. Detik demi detik, waktu yang berjalan pada bulan suci ini, ia bagaikan rangkaian berlian yang sangat berharga bagi orang beriman. Karena semuanya diberkahi dan amal ibadahnya dilipatgandakan; bulan Ramadhan adalah bulan yang di dalamnya diturunkan Alquran sebagai petunjuk bagi manusia, penjelasan bagi petunjuk, dan furqan (pembeda); bulan Ramadhan adalah bulan mulia dan agung, karena Allah sendiri telah mengagungkan dan memuliakannya, bahkan dibulan Ramadhan ini Allah menutup rapatrapat pintu Neraka dan membuka selebar-lebarnya pintu Surga. Tidak hanya itu saja, untuk balasan (pahala) bagi orang yang berpuasa dan mengerjakan amal baik dibulan Ramadhan, Allah sendirilah yang akan membalasnya.

Melihat dari paparan diatas - keutamaan bulan Ramadhan - banyak kebijakan yang dilakukan oleh pemerintah untuk menciptakan situasi dan kondisi yang mendukung untuk melakukan ibadah di bulan tersebut. Seperti halnya menutup dan menertibkan kafe/bar, tempat karaoke, lokalisasi, dan lain sebagainya

Ternyata penertiban yang dilakukan pemerintah tidak hanya yang ada di dunia nyata saja seperti yang diterangkan diatas, tetapi juga menertibkan pula yang berada di dunia tidak nyata. Sebut saja salah satunya televisi. Penertiban yang dimaksud disini adalah menertibkan isi/konten program acara di televisi selama bulan puasa Ramadhan.

Seperti apa yang dilakukan oleh lembaga KPI, dengan menggandeng MUI, berusaha dan mendorong pihak media televisi agar membuat acara dakwah dan program Ramadhan yang berkualitas. Dari artikel yang dimuat di situs resmi KPI (www.kpi.go.id) tanggal 02 April 2014, yang berjudul “MUI dan KPI Dorong Acara Dakwah dan Program Ramadhan yang Berkualitas", didapat informasi bahwa Jelang Ramadan tahun 2014, Majelis Ulama Indonesia mengadakan pertemuan dengan berbagai kalangan membicarakan konten media televisi bermuatan Islam di televisi. Pertemuan itu dihadiri dan dibuka oleh Ketua Umum MUI yang juga Ketua Umum Muhammadiyah Din Syamsuddin, kemudian Wakil Ketua Umum MUI, KH. Ma'ruf Amin, S. Sinansari Ecip, dan yang lainnya, dan dari regulator penyiaran Wakil Ketua KPI Pusat Idy Muzayyad.

Pertemuan yang bertajuk, "Halaqah Penguatan Dakwah dan Pendidikan Islam di Televisi” menghadirkan para dai dan produser televisi yang menyiarkan siaran program 
bermuatan Islam dan program Ramadan. Juga mengundang rumah produksi yang menyediakan konten media bermuatan Islam untuk televisi.

KH. Ma'ruf Amin menjelaskan perkembangan teknologi informasi masih menempatkan televisi sebagai media dakwah yang efektif. Dari hasil pantauan kajian MUI terhadap semua siaran program Ramadan, KH Ma'ruf menjelaskan menyisakan banyak catatan pada beberapa program acara yang dianggap keluar dari semangat keagamaan. Bentuk konkritnya yakni beberapa acara dakwah di televisi lebih banyak menyajikan tontonan daripada tuntunan, ada yang menyimpang hingga kurang dalam hal teladan dalam keseharian. Dan dari acara tersebut, pihak KPI dan MUI berusaha menekankan kepada seluruh elemen di stasiun televisi agar tetap mengedepankan dakwah yang santun dan efektif.

Berdasarkan pantauan dari KPI akan siaran Ramadhan untuk acara dakwah, tidak semuanya baik dan buruk. Dakwah di televisi itu berbeda dengan dakwah langsung dalam lapangan terbuka, karena dakwah disini (dakwah di televisi) pelakunya tidak tunggal melainkan tim. Dan tantangan lain dari dakwah di televisi adalah dalam kemasan acara dakwah yang menggabungkan dua hal, yakni isi materi dan kemasan yang menarik.

Dan yang terjadi saat ini memang banyak media televisi yang lebih mengutamakan kemasan yang menarik demi mendapat rating yang baik, tapi tidak memperhatikan isi materinya. Dengan demikian, menurut Wakil KPI pusat, Idy Muzayyad, pemantauan dan perbaikan acara program Ramadhan tidak bisa hanya menjadi tugas KPI semata, tapi juga MUI dan Ormas Islam yang kiranya perlu mengingatkan kembali, agar siaran Ramdhan sesuai dengan spiritnya.

Konsep yang ideal ini akan menjadi sia-sia jika tidak benar-benar dijalankan oleh stakeholder terutama para pemilik media televisi. Hal ini berdasarkan data dari hasil pantauan KPI Pusat, sebagaimana yang tertera dalam situs KPI Pusat (www.kpi.go.id) yang berjudul "Delapan Program Siaran Ramadhan Mendapat Teguran KPI Siaran Pers No. 409/K/KPI/07/13". Berdasarkan hasil pemantauan KPI Pusat, secara umum sejumlah stasiun TV telah menampilkan acara dengan semangat Ramadhan, melalui acara-acara ceramah, talkshow, features, pencarian bakat, sinetron tertentu, dan film serial. Namun, ditemukan pelanggaran isi siaran yang sama dengan pelanggaran yang dilakukan pada tahun-tahun lalu, yang dilakukan oleh beberapa acara komedi yang bersiaran langsung, 
terutama pada saat sahur. Berdasarkan Pedoman Perilaku Penyiaran (P3) dan Standar Program Siaran (SPS) 2012, terdapat empat bentuk pelanggaran yang banyak dilakukan oleh acara-acara komedi. Pertama, pelanggaran atas perlindungan kepada orang dan/atau kelompok masyarakat tertentu (melecehkan orang dengan kondisi fisik tertentu atau orang dengan orientasi seks dan identitas gender tertentu atau pekerjaan tertentu atau yang memiliki cacat fisik dan/atau mental). Kedua, pelanggaran atas perlindungan anak. Ketiga, melanggar norma kesopanan (dan kesusilaan). Keempat, melanggar ketentuan penggolongan program siaran (program klasifikasi R/Remaja).

KPI Pusat menilai secara umum tidak ada niat dari penyelenggara televisi yang menampilkan acara komedi untuk menghormati bulan Ramadhan, karena pelanggaranpelanggaran yang dilakukan merupakan pengulangan dari tahun-tahun sebelumnya. Penyelenggara televisi juga mengabaikan keluhan masyarakat terutama saat sahur dan berbuka, saat anak-anak dan remaja banyak yang memilih televisi sebagai teman santap buka dan sahur. KPI Pusat meminta semua stasiun TV untuk terus memperbaiki isi siarannya sesuai dengan semangat Ramadhan dan secara umum mematuhi Pedoman Perilaku Penyiaran dan Standar Program Siaran (P3 dan SPS) 2012. 


\section{PEMBAHASAN}

Komisi Penyiaran Indonesia (KPI) adalah sebuah lembaga independen di Indonesia yang kedudukannya setingkat dengan lembaga negara lainnya yang berfungsi sebagai regulator penyelenggaraan penyiaran di Indonesia. Komisi ini berdiri sejak tahun 2002 berdasarkan Undang-undang Republik Indonesia Nomor 32 Tahun 2002 Tentang Penyiaran. KPI terdiri atas Lembaga Komisi Penyiaran Indonesia Pusat (KPI Pusat) dan Komisi Penyiaran Indonesia Daerah (KPID) yang bekerja di wilayah setingkat Provinsi. Wewenang dan lingkup tugas Komisi Penyiaran meliputi pengaturan penyiaran yang diselenggarakan oleh Lembaga Penyiaran Publik, Lembaga Penyiaran Swasta, dan Lembaga Penyiaran Komunitas. ${ }^{1}$

Undang-undang Penyiaran Nomor 32 Tahun 2002 merupakan dasar utama bagi pembentukan Komisi Penyiaran Indonesia (KPI). Semangatnya adalah pengelolaan sistem penyiaran yang merupakan ranah publik harus dikelola oleh sebuah badan independen yang bebas dari campur tangan pemodal maupun kepentingan kekuasaan.

Apabila ditelaah secara mendalam, Undang-undang no. 32 Tahun 2002 tentang Penyiaran lahir dengan dua semangat utama, pertama pengelolaan sistem penyiaran harus bebas dari berbagai kepentingan karena penyiaran merupakan ranah publik dan digunakan sebesar-besarnya untuk kepentingan publik. Kedua adalah semangat untuk menguatkan entitas lokal dalam semangat otonomi daerah dengan pemberlakuan sistem siaran berjaringan.

Maka sejak disahkannya Undang-undang no. 32 Tahun 2002 terjadi perubahan fundamental dalam pengelolaan sistem penyiaran di Indonesia, dimana pada intinya adalah semangat untuk melindungi hak masyarakat secara lebih merata. Perubahan paling mendasar dalam semangat UU ini adalah adanya limited transfer of authority dari pengelolaan penyiaran yang selama ini merupakan hak ekslusif pemerintah kepada sebuah badan pengatur independen (independent regulatory body) bernama Komisi Penyiaran Indonesia (KPI). Independen yang dimaksudkan adalah untuk mempertegas bahwa pengelolaan sistem penyiaran yang merupakan ranah publik harus dikelola oleh sebuah badan yang bebas dari intervensi modal maupun kepentingan kekuasaan. Belajar dari masa lalu dimana pengelolaan sistem penyiaran masih berada ditangan pemerintah

\footnotetext{
${ }^{1}$ http://kpi.go.id/index.php/2012-05-03-14-44-06/2012-05-03-14-44-38/profil-kpi
} 
(pada masa rezim orde baru), sistem penyiaran sebagai alat strategis tidak luput dari kooptasi negara yang dominan dan digunakan untuk melanggengkan kepentingan kekuasaan. Sistem penyiaran pada waktu itu tidak hanya digunakan untuk mendukung hegemoni rezim terhadap publik dalam penguasaan wacana strategis, tapi juga digunakan untuk mengambil keuntungan dalam kolaborasi antara segelintir elit penguasa dan pengusaha.

Berbicara mengenai kebijakan terhadap publik atau kebijakan publik, menitikberatkan pada apa yang oleh Dewey² katakan sebagai "publik dan problemproblemnya." Kebijakan publik membahas soal bagaimana isu-isu dan persoalanpersoalan tersebut disusun (constructed) dan didefinisikan, dan bagaimana kesemuanya itu diletakkan dalam agenda kebijakan dan agenda politik. Selain itu, kebijakan publik juga merupakan studi tentang "bagaimana, mengapa, dan apa efek dari tindakan aktif (action) dan pasif (inaction) pemerintah". ${ }^{3}$ Atau, seperti dinyatakan oleh Dye, kebijakan publik adalah studi tentang "apa yang dilakukan oleh pemerintah, mengapa pemerintah mengambil tindakan tersbut, dan apa akibat dari tindakan tersebut". ${ }^{4}$

Dan dalam sebuah kebijakan pemerintah, disyaratkan menurut perhitungan pemerintah harus terdapat maslahah bagi kesejahteraan rakyat, sebagaimana prinsip dasar politik yang telah digariskan oleh beliau Imam Syafi'i Ra: "Kebijakan pemerintah harus berdasarkan demi kesejahteraan rakyat." 5

Perhitungan akan kemaslahatan yang timbul dari suatu kebijakan merupakan wewenang pemerintah dengan berbagai pertimbangan yang telah digariskan syara'. Maka kita pemerintah sudah benar-benar memperhitungkan kebijakan tersebut akan mendatangkan kebaikan, keuntungan, menghindari kerusakan atau menanggulangi kerugian yang lebih besar demi kepentingan rakyat secara umum, kebijakan tersebut bisa dibenarkan. ${ }^{6}$

Seperti halnya gagasan "publik," ide kebijakan menurut Heclo bukanlah sebuah istilah yang pasti atau swabukti (self-evident): dikatakan bahwa kebijakan (police) adalah

\footnotetext{
${ }^{2}$ J. Dewey, The Public and its Problem, Holt, New York, 1927.,

${ }^{3}$ A. Heidenheimer, H. Hecto and C.T. Adams, Comparative Public Policy: The Politics of Social Choice in America, Europe, and Japan, (New York: St. Martin's Press, 1990), hal. 3.

${ }^{4}$ T.R. Dye, What Goverments Do, Why They do it, What Difference it Makes, (Tuscaloosa: University of Alabama Press, 1976). hal. 1.

5 Tim Bahtsul masa-il, Mutiara Samudra Fiqh (Metode Penalaran Solusi Fiqhiyyah), (Kediri: Forum Pembukuan Bahtsul Masa-il Purna Siswa MHM. Lirboyo, 2004), 251.

6 Ibid., 251.
} 
istilah yang tampaknya banyak disepakati bersama. Dalam penggunaannya yang umum, istilah kebijakan dianggap berlaku untuk gerakan sosial. Jadi, kebijakan, dari sudut pandang tingkat analisis, adalah sebuah konsep yang kurang lebih berada di tengahtengah. Elemen kedua dan esensial yang terkandung dalam penggunaan istilah itu oleh kebanyakan penulis adalah aspek tujuannya. ${ }^{7}$

\section{Analisis dan Proses Kebijakan}

Analisis mengandung tujuan dan relasi yang berbeda dengan proses kebijakan. Kita bisa menganggap jenis analisis kebijakan ini sebagai terdiri dari rangkaian aktivitas pada spectrum pengetahuan dalam (in) proses kebijakan; pengetahuan untuk (for) proses kebijakan; dan pengetahuan tentang (about) proses kebijakan.

Analisis ini mencakup:

1. Determinasi kebijakan: ini adalah analisis yang berkaitan dengan cara pembuatan kenijakan, mengapa, kapan, dan untuk siapa kebijakan dibuat;

2. Isi kebijakan: analisis ini mencakup deskripsi tentang kebijakan tertentu dan bagaimana ia berkembang dalam hubungannya dengan kebijakan sebelumnya, atau analisis ini bisa juga didasari oleh informasi yang disediakan oleh kerangka nilai/teoritis yang mencoba memberikan kritik terhadap kebijakan.

\begin{tabular}{|c|}
\hline Analisis \\
Kebijakan \\
\hline
\end{tabular}

Analisis Untuk Kebijakan
1

Analisis determinasi Kebijakan
2

Analisis Isi

Kebijakan
3

Monitoring dan evaluasi Kebijakan
4

Informasi untuk

Kebijakan
5

Advokasi Kebijakan

\section{Gambar 1. Variasi Analisis Kebijakan}

Sumber diadaptasi dari Gordon, et al. (1977)

\footnotetext{
${ }^{7}$ H. Heclo, Review Article: Policy Analysis, British Journal of Political Science, 2:, hal. 84
} 


\section{Monitoring dan Evaluasi Kebijakan}

Fokus analisis ini adalah mengkaji bagaimana kinerja kebijakan dengan mempertimbangkan tujuan kebijakan, dan apa dampak kebijakan terhadap suatu persoalan tertentu.

Analisis ini mencakup:

1. Advokasi kebijakan: berupa riset dan argument yang dimaksudkan untuk memengaruhi agenda kebijakan di dalam dan atau di luar pemerintah.

2. Informasi untuk kebijakan: sebentuk analisis yang dimaksudkan untuk member informasi bagi aktivitas pembuatan kebijakan. Ini bisa berbentuk anjuran atau riset eksternal/internal yang terperinci tentang aspek kualitatif dan judgemental dari suatu kebijakan.

\section{Implementasi}

Studi implementasi adalah studi perubahan: bagaimana perubahan terjadi, bagaimana kemungkinan perubahan bisa dimunculkan. la juga merupakan studi tentang mikrostruktur dari kehidupan politik; bagaimana organisasi di luar dan di dalam sistem politik menjalankan urusan mereka dan berinteraksi satu sama lain; apa motivasi-motivasi mereka bertindak seperti itu, dan apa motivasi lain yang mungkin membuat mereka bertindak secara berbeda. ${ }^{8}$

Pembuatan kebijakan tidak berakhir setelah kebijakan ditentukan atau disetujui. Seperti dinyatakan Anderson: "Kebijakan dibuat saat ia sedang diatur dan diatur saat sedang dibuat."9 Implementasi adalah pelaksanaan pembuatan kebijakan dengan caracara lain. Akan tetapi biasanya kita cenderung menganggap sistem politik sebagai sesuatu yang menambah problem, dengan menarik garis pemisah antara kebijakan dan administrasi. Administrasi, menurut sudut pandang ini, akan mengambil alih setelah kebijakan selesai. Pekerjaan administrasi adalah melaksanakan kebijakan yang dirumuskan oleh pembuat kebijakan, dan peran penyedia layanan adalah menjalankan kebijakan yang diatur oleh birokrat. Hubungan dan interaksi antara politisi, administrator,

\footnotetext{
${ }^{8}$ W.I. Jenkins, Policy Analysis: A Political and Organizational Perspective, (London: Martin Roberstson, 1978), hal. 203.

9 J.E. Anderson, Public Policy-making, (New York: Holt Praeger, 1975), hal. 98.
} 
dan penyedia layanan hingga saat ini masih dilupakan dalam area analisis dan riset: ini adalah semacam "missing linki" dalam proses kebijakan.

\section{Pendekatan Sistem Rasional Top-Down}

Pendekatan top-down ini memiliki pandangan tentang hubungan kebijakanimplementasi seperti yang tercakup dalam Emile karya Rousseau: "Segala sesuatu adalah baik jika diserahkan ke tangan Sang Pencipta. Segala sesuatu adalah buruk di tangan manusia." Model rasional ini berisi gagasan bahwa implementasi adalah menjadikan orang melakukan apa-apa yang diperintahkan, dan mengontrol urutan tahapan dalam sebuah sistem; dan implementasi adalah soal pengembangan sebuah program kontrol yang meminimalkan konflik dan deviasi dari tujuan yang telah ditetapkan oleh "hipotesis kebijakan" ${ }^{10}$ Andrew Dunsire, misalnya, mengemukakan sebuah "model rasionalis" yang sengaja mengesampingkan semua soal "cinta, benci, cemburu, dan factor motivasional apa pun." Jika implementasi gagal, yakni tujuan kebijakan tak tercapai-mungkin itu disebabkan oleh faktor seperti pemilihan strategi yang keliru, atau "mesin" atau "instrument" yang keliru; "pemrograman" birokrasinya salah; operasioanalisasinyaburuk; ada yang salah pada "tingkat pelaksana"; atau respons yang buruk terhadap problem. ${ }^{11}$

\section{PENUTUP}

Pada dasarnya proses tahapan kebijakan yang ada lembaga KPI sudah berjalan sesuai dengan koridor hukum. Dimana dengan adanya Undang-undang Penyiaran Nomor 32 Tahun 2002 merupakan dasar utama bagi pembentukan Komisi Penyiaran Indonesia $(\mathrm{KPI})$. Sehingga dari Undang-undang tersebut memiliki nilai semangat pengelolaan sistem penyiaran yang merupakan ranah publik harus dikelola oleh sebuah badan independen yang bebas dari campur tangan pemodal maupun kepentingan kekuasaan.

Dan apabila ditelaah secara mendalam, Undang-undang no. 32 Tahun 2002 tentang Penyiaran lahir dengan dua semangat utama, pertama pengelolaan sistem

\footnotetext{
${ }^{10}$ J. Pressman and A. Wildavsky, Implementation, (Berkeley: University of Californi Press, 1973), hal. Xiii.

${ }^{11}$ Andrew Dunsire, Implementation Theory and Bureaucrancy, (In Younis, 1990), hal. 15.
} 
penyiaran harus bebas dari berbagai kepentingan karena penyiaran merupakan ranah publik dan digunakan sebesar-besarnya untuk kepentingan publik. Kedua adalah semangat untuk menguatkan entitas lokal dalam semangat otonomi daerah dengan pemberlakuan sistem siaran berjaringan.

Jika secara teoritis, maka kebijakan yang dikeluarkan oleh lembaga KPI adalah sudah kuat secara hukum dan harus dipatuhi oleh segala pihak yang berkaitan dengan lembaga KPI. Namun dalam realitanya masih ada yang belum melaksanakan.

Dan ketika dikaitkan dengan teori-teori diatas, faktor-faktor yang menyebabkan impelementasi gagal terlaksana diantaranya disebabkan oleh faktor seperti pemilihan strategi yang keliru, atau "mesin" atau "instrument" yang keliru; "pemrograman" birokrasinya salah; operasioanalisasinya buruk; ada yang salah pada "tingkat pelaksana"; atau respons yang buruk terhadap problem. Dari beberapa faktor tersebut, bisa jadi faktor yang ada di tubuh KPI adalah buruknya tingkat pelaksana kebijakan. Kurang tegasnya sanksi yang diberikan, sehingga membuat lembaga KPI tidak memiliki wibawa di mata para stakeholder media. Dan bisa juga buruknya instrument birokrasinya. Seperti yang diberitakan dalam media Rakyat Merdeka Online, 23 Maret 2011, bahwa UU 32/2002 tentang Penyiaran masih menjadi target revisi. DPR memasukkannya kembali ke dalam proglenas 2011 sebagai usul insiatif Dewan. ${ }^{12}$

Jadi disini seakan-akan ada upaya dari pihak media yang kongkalikong dengan pemerintah. Padahal UU Penyiaran yang dibuat saat itu ruangnya sangat demokratis," dan posisi Komisi Penyiaran Indonesia semakin diperparah lagi bahkan justru dikebiri dengan dikeluarkannya Peraturan Pemerintah 50/2005. Tugas KPI pun hanya mengawasi kontens saja dan tidak bisa memberi sanksi kepada media penyiaran yang melanggar UU Penyiaran.

\section{REFERENSI}

Anderson, J.E. Public Policy-making, New York: Holt Praeger, 1975.

Dewey, J. The Public and its Problem, Holt, New York

Dunsire, Andrew Implementation Theory and Bureaucrancy, In Younis, 1990. Juni 2019.

12 http://www.rmol.co/read/2011/03/23/21920/KPI-Lemah-Hadapi-Konglomerat-, diakses tanggal 27 
Dye, T.R. What Goverments Do, Why They do it, What Difference it Makes, Tuscaloosa: University of Alabama Press, 1976.

Heclo, H. Review Article: Policy Analysis, British Journal of Political Science,2.

Heidenheimer, A. H. Hecto and C.T. Adams, Comparative Public Policy: The Politics of Social Choice in America, Europe, and Japan, New York: St. Martin's Press, 1990.

Jenkins, W.I. Policy Analysis: A Political and Organizational Perspective, London: Martin Roberstson, 1978.

Pressman J. and A. Wildavsky, Implementation, Berkeley: University of Californi Press, 1973.

Tim Bahtsul masa-il, Mutiara Samudra Figh (Metode Penalaran Solusi Fiqhiyyah), Kediri: Forum Pembukuan Bahtsul Masa-il Purna Siswa MHM. Lirboyo, 2004 http://www.rmol.co/read/2011/03/23/21920/KPI-Lemah-Hadapi-Konglomerat-, http://.kpi.go.id 